\title{
Briefing: Disruptive socio-technical solutions to drive re-visualisation of water service provision
}

1 Issy Caffoor BSC, PDip, Biom, PhD Visiting Professor, The University of Sheffield, Sheffield, UK

2 Vanessa Speight BEng, MSEE, PhD, PE Senior Research Fellow, The University of Sheffield, Sheffield, UK
3 Joby Boxall MEng, PhD, CEng, CEnv, FCIWEM Professor, The University of Sheffield, Sheffield, UK (corresponding author: j.b.boxall@sheffield.ac.uk) (Orcid:0000-0002-4681-6895)
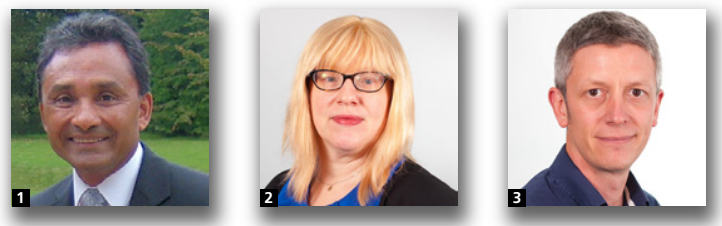

The UK Engineering and Physical Sciences Research Council has launched a $\mathrm{f4}$ million, 5-year grand challenge multi-disciplinary research consortium (Twenty65) to achieve sustainable clean water for all through the development and demonstration of disruptive socio-technical solutions. The aim of this transformative research is to drive re-visualisation of water service provision and revolutionise the way innovation is delivered in the water sector. This briefing introduces concepts of disruptive innovation that could lead to a new paradigm for water service provision.

\section{Introduction}

Safe and secure water supply is fundamental to society (HMG, 2011a) but is faced with global challenges from climate change, water stress, carbon dioxide reduction targets, demographic change, urbanisation and cost. This situation is compounded by increasing societal expectations and regulation, along with ageing, deteriorating and rigid infrastructure. Within the UK, inferred buried sewer and clean water asset lives are on the order of 800 and 120 years, respectively, based on price review settlements (HMG, 2011b). The water sector is in this position despite escalating levels of spending, such as the $£ 44$ billion of private investment planned for water infrastructure in 2015-2020 (Ofwat, 2014). Extrapolation of increasing failure rates at the current levels of investment leads to the worst case scenario of catastrophic system failure. There are also strong regulatory, societal and economic drivers to improve water service provision and to protect the natural water environment.

There is a clear need for disruptive innovation to achieve flexible and adaptive water systems; that is, innovation that offers radically different alternatives to the current approach, transforming the current infrastructure service delivery model. Engineering cannot solve the water grand challenges alone - it is not sustainable or desirable to 'build' our way out of the current situation. Furthermore, it is impossible for any single universal 'silver bullet' technology to solve all the interconnecting and interacting challenges and changing requirements. Instead, the Twenty65 consortium proposes the development of 'silver baskets' of integrated tailored solutions to achieve the necessary transformation.

\section{A systems approach through thought leadership}

The research themes, outlined later in the paper, were derived through a robust sector-wide thought leadership club (TLC) process such that greatest potential for transformation is through their integration and combination. An initial workshop with participants from across the water sector identified three key areas of focus for research on water systems - buried infrastructure performance, zero failures, and resource recovery and efficiency (Figure 1). A series of open TLC workshops then explored each of these areas using novel creativity and co-creation methods (Birdi, 2016) to diagnose the problems and issues to be addressed. These were then drawn together to identify themes that could individually disrupt across multiple challenges; some key linkages are shown in Figure 1. The ultimate transformation will be achieved by combining multiple aspects of such themes, tailored to meet context specific challenges, to deliver sustainable clean water for all. The following paragraphs aim to illustrate how such socio-technical solutions could combine to provide radically different resilient and adaptable futures, rather than to provide a discussion or critique of current issues.

The current water service delivery paradigm is reliant on centralised, ageing, rapidly deteriorating, buried infrastructure to supply clean water and carry away waste water. Continued use 


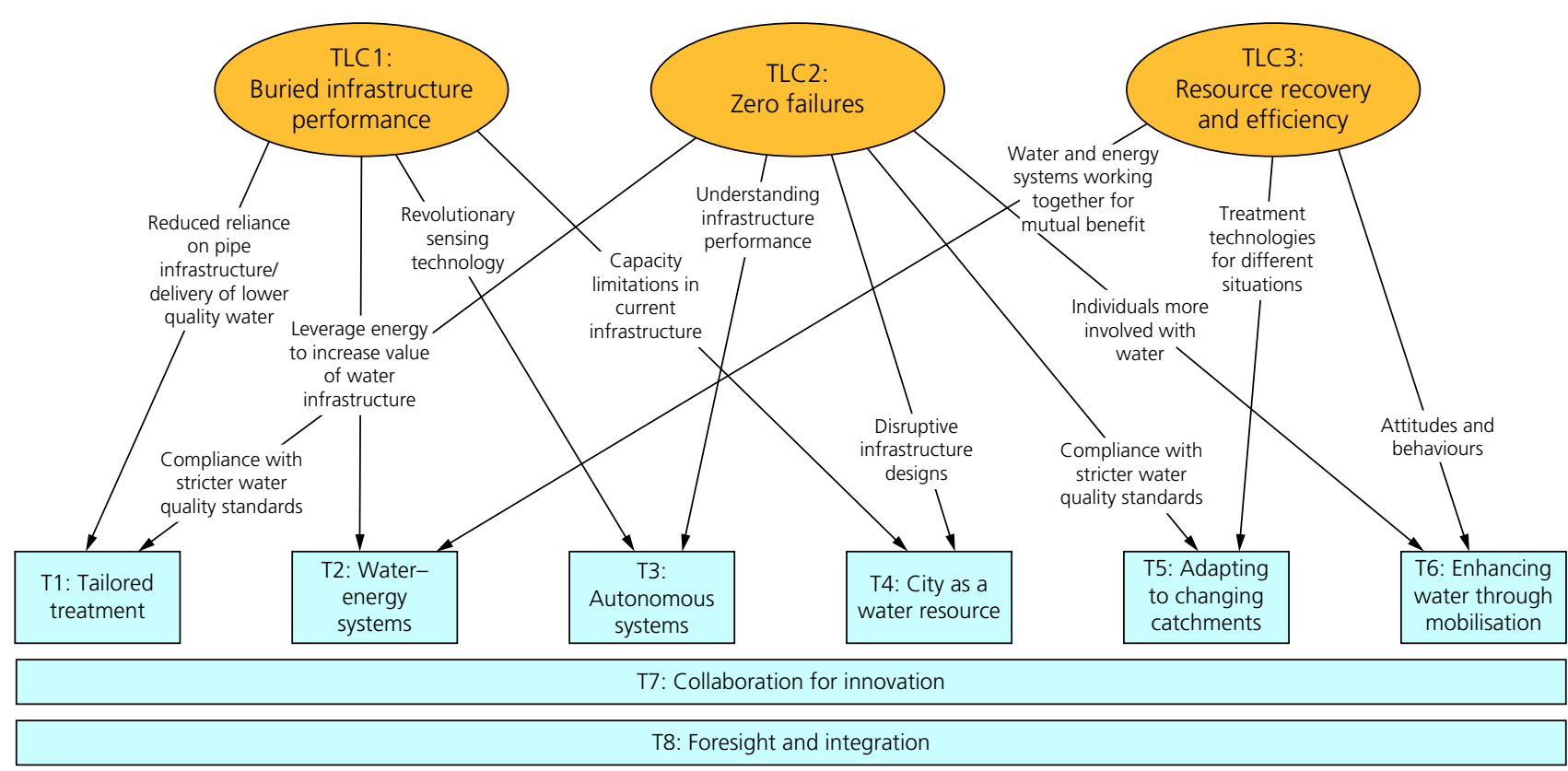

Figure 1. Mapping from key challenge areas to selected socio-technical themes

of this infrastructure requires either a revolution in sensing to provide comprehensive information about the system at all times, or a reduction in reliance on pipe infrastructure by providing services in an alternate form. Advances in autonomous robotics offer the potential to transform management by mapping and assessment of buried infrastructure using pervasive sensing, such that highly cost-effective asset rehabilitation techniques can be applied just in time. Further, if such performance data are always available, there is the potential to leverage value across infrastructure by opening the capacity of water infrastructure to help meet the distributed energy storage challenges as we move towards distributed renewables. Likewise, if transformations in the scale, scope, robustness and reliability of water treatment made it possible to treat water to the necessary quality at its point of use, the buried infrastructure could be allowed to carry a lower quality of water and its deterioration would become less significant. In conjunction with this new treatment paradigm, local low-volume sources from green infrastructure such as sustainable urban drainage and rainwater harvesting could be utilised to deliver multiple benefits across surface water management and water supply, transforming their value and uptake.

Although $100 \%$ compliance with regulations is the current goal of the water industry, this has not been achieved. The management of buried infrastructure plays a significant role in meeting compliance objectives. Consideration of disruptive infrastructure designs, such as the multiple benefits of sustainable drainage installations for both surface water management and as water supply sources, could offer a way to boost compliance with the appropriate monitoring and quality assurance and robust and reliable decentralised treatment. As standards to protect human health and the environment become stricter, the water industry will need pollutant data from catchments in real-time to optimise treatment in terms of both cost and effectiveness. Furthermore, increased involvement of individuals throughout the water cycle could offer non-technical solutions to pressing problems. For example, if people did not pour fats, oils and greases down their drains, solutions for fat, oil and grease removal in sewers would no longer be required.

The water industry is beginning to view waste products as a resource, particularly for energy and nutrient recovery. The linkage between water and energy infrastructure is natural given they are systems with nearly identical urban footprints and, in the future, these could be more intricately linked, providing localised energy storage, heat transfer and recovery, and energy generation. Initial estimates of the potential energy (10-20 GWh/d, based on a few tens of centimetres recovered for each $1 \mathrm{~m}^{3}$ water/wastewater) and heat recovery (30-80 GWh/d, based on $25-50 \%$ heat recovery, assuming a 9 MW recovery rate from 79500PE) (Abdel-Aal, 2016) in UK urban water systems are of the same order as the UK's daily electricity variation $(200 \mathrm{GWh} / \mathrm{d})$. The recovery of nutrients, precious metals and related materials from wastewater has begun to take place, but new treatment technologies will be required to make the extraction of resources easier, cheaper and more sustainable. A change in attitude from the public will also be required.

To enable collaborative, long-term, responsible innovation, which is currently lacking but is essential for success in 
transforming water systems, several supporting elements need to be in place. An understanding of the barriers to collaboration and how they can be overcome by the sector as a whole is essential, as is foresight in thinking about the possible future threats and performance criteria for water systems. To provide the support for these sector-wide activities, the Water Innovation $\mathrm{Hub}$ is a critical part of the transformation of water systems. Activities run by the hub include workshops, an annual conference and the development of a shared roadmap as a blueprint for further research to be pursued by TLC members and the wider water research community.

\section{Research themes}

A series of sector-endorsed themes emerged from the systems thinking and co-creation of the TLC workshops. The themes are evidence of what is possible through creative transformative approaches and how they - when designed and implemented taking a systems approach as described previously - could collectively deliver robust, reliable and sustainable solutions for water service provision in the long term. It is not suggested that these themes provide definitive solutions or are an exhaustive list of what is required, but rather that they are leading examples of components of what is needed for the necessary transformative change. For each theme, the underpinning disruptive premise is presented.

\subsection{Demand-based technologies for tailored treatment}

This theme asks whether game-changing treatment tailored for specific demands could provide more sustainable alternatives to the current centralised paradigms. Feasibility studies will explore physical, chemical and biological options. Initial work is yielding promising results for low-head graphene oxide membranes.

\subsection{Synergistic water-energy systems to minimise carbon dioxide emissions}

This theme proposes that realising the distributed latent capacity in water systems could play a significant role in meeting energy storage and generation challenges as we move towards decentralised renewable sources.

\subsection{Robotic autonomous systems for water infrastructure}

The aim of this theme is to develop micro-machine technology suitable for deployment in buried pipe infrastructure for the purposes of perpetual mapping and inspection. The vision is that human intervention will become unnecessary as it is replaced by pervasive autonomous systems that will facilitate asset rehabilitation at the right time when the rehabilitation costs and operation risks are minimal. Research in this area is resulting in novel sensing solutions for detection of loss of pipe support/void formation from within the pipe.

\subsection{The city as a water resource}

This theme will challenge traditional silos by generating evidence of the multiple benefits of integrated urban water management and reuse at multiple scales. A major innovation to be enabled is the change in management/governance structures required to underpin the implementation of cost-effective multi-function systems.

\subsection{Adapting to changing catchments}

This theme seeks to understand treatment requirements to ensure reliable drinking water quality as source water quality changes due to extreme weather and longer-term environmental change. The theme is seeking to develop treatability measures and functional relationships based on real-time continuous monitoring sensors and through integration with catchment hydrology models.

\subsection{Enhancing water services through mobilisation}

This theme looks at how and why collective working can effectively mobilise change. The theme will study and develop suitable mobilisation initiatives to engage people/stakeholders in taking action so that collective water services can be delivered more efficiently and/or with reduced environmental impact.

\subsection{Collaboration for innovation}

This theme will seek to radically improve collaboration across each stage of the innovation process. The research will identify the factors influencing the effectiveness of collaboration between all stakeholders within the innovation process, and develop, test and implement a new practical model for the UK water sector to guide collaborations in the innovation process. The toolset 'Clear Ideas' has been adapted for the water sector and used effectively by the authors and others for the generation and delivery of creative innovation.

\subsection{Foresight and integration}

This theme will aim to understand and forecast changes in environmental and anthropogenic activities. The research will develop perspectives of water futures and tools that, by addressing longterm drivers and pressures, will provide assessment methods to help navigate water futures and stress test 'silver baskets' of solutions. Rather than adding to the plethora of future scenarios, the aim is to deliver concepts to progress towards route maps.

\section{Summary}

The consortium has initiated core activity and the hub structure and functions are now well founded. The consortium is thus now looking to expand and grow its reach, with spinoff activities starting to progress. If you would like to learn more or get involved, please visit http://www.twenty65.ac.uk. The first annual conference, aimed at bringing academia, water companies, supply chain, regulators and all water stakeholders together to interact and debate the grand challenges facing UK water will be held on 4-5 April 2017. 
The future to be inspired and enabled by the research is that, by 2065, collaborative accelerated innovation has generated a dynamic and energised water sector that is delivering sustainable tailored water solutions that positively impact on public health, the environment, the economy and society.

\section{Five-year programme}

Following an announcement from the Science Minister, Jo Johnson, in October 2015, the research programme started at the end of January 2016 and involves a multi-disciplinary consortium from the Universities of Sheffield, Exeter, Manchester, Reading, Newcastle and Imperial College. Led by Joby Boxall from The University of Sheffield, the research is sponsored by EPSRC grant number EP/N010124/1.

\section{REFERENCES}

Abdel-Aal M (2016) Modelling the Viability of Heat Recovery from Underground Pipes. PhD thesis, University of Bradford, Bradford, UK.

Birdi KS (2016) Creativity training. In Human Resource Management, Innovation and Performance (Shipton $\mathrm{H}$, Budhwar P, Sparrow $\mathrm{P}$ and Brown A (eds)). Palgrave Macmillan, London, UK, pp. 298-312.

Her Majesty's Government (HMG) (2011a) National Infrastructure Plan. HMG, London, UK. See http://www.gov.uk/government/ publications/national-infrastructure-plan-november-2011 (accessed 21/11/2016).

HMG (2011b) Water for Life. HMG, London, UK. See http://www.gov. uk/government/uploads/system/uploads/attachment_data/file/ 228861/8230.pdf (accessed 20/01/2017).

Ofwat (2014) Setting Price Controls for 2015-20. Ofwat, Birmingham, UK. See http://www.ofwat.gov.uk/wp-content/uploads/2015/10/det pr20141212final.pdf (accessed 08/12/2016).

\section{How can you contribute?}

To discuss this briefing, please email up to 500 words to the editor at journals@ice.org.uk. Your contribution will be forwarded to the author(s) for a reply and, if considered appropriate by the editorial board, it will be published as discussion in a future issue of the journal.

Proceedings journals rely entirely on contributions from the civil engineering profession (and allied disciplines). Information about how to submit your paper online is available at www.icevirtuallibrary.com/page/authors, where you will also find detailed author guidelines. 